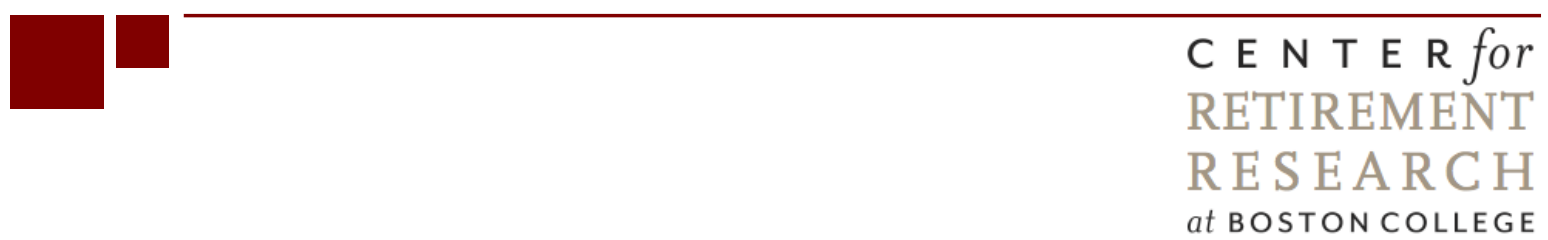

\title{
HOW DO SUBJECTIVE MORTALITY BELIEFS AFFECT THE VALUE OF SOCIAL SECURITY AND THE OPTIMAL CLAIMING AGE?
}

Wei Sun and Anthony Webb

CRR WP 2011-22

Date Released: November 2011

Date Submitted: November 2011

\author{
Center for Retirement Research at Boston College \\ Hovey House \\ 140 Commonwealth Avenue \\ Chestnut Hill, MA 02467 \\ Tel: 617-552-1762 Fax: 617-552-0191 \\ http://crr.bc.edu
}

Wei Sun is with the Hanqing Advanced Institute of Economics and Finance and School of Finance at the Renmin University of China, and Anthony Webb is a research economist at the Center for Retirement Research at Boston College. The research reported here was performed pursuant to a grant from the U.S. Social Security Administration (SSA) funded as part of the Retirement Research Consortium (RRC). The opinions and conclusion expressed are solely those of the author and do not represent the opinions or policy of SSA, any agency of the federal government, the RRC, or Boston College.

(C) 2011, Wei Sun and Anthony Webb. All rights reserved. Short sections of text, not to exceed two paragraphs, may be quoted without explicit permission provided that full credit, including (C) notice, is given to the source. 


\begin{abstract}
About the Center for Retirement Research
The Center for Retirement Research at Boston College, part of a consortium that includes parallel centers at the University of Michigan and the National Bureau of Economic Research, was established in 1998 through a grant from the Social Security Administration. The Center's mission is to produce first-class research and forge a strong link between the academic community and decision-makers in the public and private sectors around an issue of critical importance to the nation's future. To achieve this mission, the Center sponsors a wide variety of research projects, transmits new findings to a broad audience, trains new scholars, and broadens access to valuable data sources.
\end{abstract}

\author{
Center for Retirement Research at Boston College \\ Hovey House \\ 140 Commonwealth Avenue \\ Chestnut Hill, MA 02467 \\ phone: 617-552-1762 fax: 617-552-0191 \\ e-mail: crr@bc.edu \\ crr.bc.edu
}

Affiliated Institutions:

The Brookings Institution

Massachusetts Institute of Technology

Syracuse University

Urban Institute 


\begin{abstract}
Households that delay claiming Social Security are, in effect, making additional purchases of the Social Security annuity. Theoretical calculations show the delayed claiming is optimal, even for high mortality households. Yet most claim well before the theoretically optimal age. This paper investigates whether subjective mortality beliefs contribute to the prevalence of early claiming. The value of delay depends not only on life expectancy, but also on the degree of uncertainty surrounding the age of death. Using data from the Health and Retirement Study, we show that women approaching retirement understate their probabilities of surviving to age 75 by an average of 10 percentage points, whereas men's forecasts are, on average, correct. But both men and women exhibit greater confidence of their ability to forecast their age of death, relative to the predictions of life tables. But these subjective mortality beliefs have little effect on the value of Social Security or the optimal claim age, and cannot explain the prevalence of early claiming. We also find that self-assessed survival probabilities do not predict survival after controlling for health and socio-economic status, indicating a potential for medical underwriting to reduce adverse selection in the annuity market.
\end{abstract}




\section{Introduction}

One of the central predictions of the life-cycle model of savings behavior is that consumption, savings, and annuitization decisions are influenced by subjective mortality beliefs. These decisions should be influenced not only by how long the individual expects to live but also by the degree of uncertainty regarding the individual's age of death. At one extreme, an individual who can forecast his age of death with certainty will value an annuity at the present value of the income stream to the age of death. This is because he can decumulate unannuitized wealth over a period ending with his date of death. At the other extreme, an individual with the same life expectancy but who is highly uncertain as to his age of death will value an annuity at considerably more than its expected present value because he will otherwise need to substantially reduce his consumption to guard against the perceived high risk of outliving his wealth.

Social Security provides benefits in the form of an inflation-indexed annuity. An individual who delays claiming receives an increase in his monthly benefit with delay being equivalent to an annuity purchase. He can be thought of as returning this month's check to the Social Security Administration in return for an increase in his lifetime income. The value of delay will be greater for those individuals with greater life expectancy. It will also be greater for those who are most uncertain as to their age of death. Sun and Webb (2010) show that, given plausible preference parameters, it is optimal for households with population average annual mortality risk to delay claiming until age 68. Yet most households claim benefits at age 62 or soon thereafter, even when they have sufficient financial assets to postpone claiming until after retirement. 
Making use of data from the Health and Retirement Study (HRS), this paper assesses whether individuals’ subjective mortality beliefs exhibit systematic biases, and whether any such biases might contribute to the prevalence of early claiming of Social Security benefits. ${ }^{1}$ Starting in 1992, individuals in the HRS have been asked to assess their probabilities of surviving to ages 75 and 85. Previous research (Hurd and McGarry 1995, 2002) has shown that responses vary appropriately with risk factors and predict mortality during a two-year period. A substantial portion of the individuals interviewed in 1992 have now either died or reached age 75, providing an opportunity for us to extend research by comparing subjective mortality beliefs with actual survival to age 75 . We show that self-assessed survival probability strongly predicts actual survival, but that it is statistically insignificant after controlling for observable health status and socioeconomic characteristics, indicating that responses do not incorporate private mortality information. We show that, on average, men form unbiased estimates of their survival probabilities, but that women understate their survival probabilities by 10 percentage points. We also show that, relative to the predictions of an econometric model based on observable health and socioeconomic status, those who survive to age 75 understated their survival probabilities by more than those who die by that age. We find that the ability to form accurate and unbiased estimates of the probability of surviving to age 75 is generally uncorrelated with socio-economic or health status.

\footnotetext{
${ }^{1}$ The Health and Retirement Study is a nationally representative panel dataset of individuals born between 1931 and 1941 and their spouses of any age. They have been interviewed every two years since 1992, with younger birth cohorts joining in 1998, 2004, and 2010.
} 
The responses suffer from focal point bias, with considerable bunching of responses at zero, 50, 100 percent, and so on. It is not clear how to treat these responses. Do individuals literally mean that they rate their survival probability at zero or 100 percent, or somewhere close to these numbers? In 2008, individuals who gave focal-point responses were asked follow-up questions designed to elicit information regarding their underlying beliefs. We find that although individuals who are unable to provide any estimate of their survival probabilities are significantly more likely to be members of minorities, be in poor health, and to have less than a high school education, there are few consistent and significant differences in either socio-economic characteristics or mortality rates between those who state that their estimates are precise, and those who say that they are approximations.

Previous research into subjective mortality beliefs has focused on whether people are capable of forming unbiased estimates of their life expectancy, and has not considered the question of whether people can accurately quantify the degree of uncertainty surrounding their age of death. We find some evidence that households not only underestimate their longevity, but also exhibit greater confidence in their ability to forecast their age of death, relative to estimates that assume they experience the average mortality rate of individuals of their age, gender, and birth cohort. We cannot infer from this finding that people are excessively confident. It is likely that individuals do possess information that enables them to improve on the confidence intervals that would be obtained from the use of life tables. 
We recover annual survival probabilities from subjective mortality beliefs and use these annual survival probabilities to calculate optimal Social Security claiming strategies. We show that although the subjective survival probabilities differ substantially from the predictions of life tables, they have little effect on optimal strategies. These theoretical calculations are consistent with empirical studies (Coile, Diamond, Gruber, and Jousten, 2002, Hurd, Smith, and Zissimopoulos, 2004) showing that subjective mortality beliefs appear to have little effect on the claiming decision.

The remainder of the paper is organized as follows. In Section 1, we review previous research. In Section 2, we analyze HRS respondents' self-assessed survival probabilities, identify biases, and recover subjective annual survival probabilities from individuals' responses. In Section 3, we present a theoretical model of the Social Security claiming decision, and consider how the optimal claiming age might be affected by subjective mortality beliefs. Section 4 concludes.

\section{Previous Research}

Research on subjective mortality beliefs

Hurd and McGarry (1995) analyzed subjective survival probability estimates provided by participants in the 1992 wave of the HRS. They showed that these estimates aggregate to life-table probabilities and co-vary with risk factors. Hurd and McGarry(2002) show that the above beliefs are predictive of subsequent mortality over a two-year time horizon and respond in panel to the receipt of new information. Sondergeld, Drinkwater, and Jamison (2002) find that, on average, individuals approaching retirement mis-state life expectancy 
by only small amounts. ${ }^{2}$ In contrast, Elder (2007) finds that, relative to the predictions of life tables, HRS participants are pessimistic about their chances of surviving to age 75 but optimistic about their chances of surviving to age $85 .{ }^{3}$ He finds that higher subjective survival probabilities are associated with households holding a larger proportion of their wealth in stocks. But this relationship does not hold for individuals who assess their survival probability at 100 percent, suggesting that these individuals may differ in some significant way from those whose responses are close to, but less than, 100 percent. $^{4}$

A problem arises in the interpretation of responses of zero and 100 percent. Even if these responses represent the individual's true beliefs, we cannot infer estimates of the probabilities of survival to other ages from these responses. Many other individuals provide what may well be focal-point responses of, for example, 50 percent. Gan, Hurd, and McFadden (2005) propose a Bayesian updating methodology for recovering the individual's true underlying beliefs. Although their approach produces life tables that vary with individuals' responses, it is not self-evident that these tables better reflect individuals' true underlying beliefs than the raw responses.

\footnotetext{
${ }^{2}$ Their benchmark is the Annuity 2000 Basic Life Table. This table estimates the mortality risk of annuitants and yields significantly lower mortality rates than the population life tables used by other researchers.

${ }^{3}$ Our analyses of 2008 data indicate that after excluding those individuals reporting that $p_{85}>p_{75}$ the remainder of the sample is no longer optimistic about its probability of surviving to age 85 . Clearly, $p_{85}$ cannot exceed $p_{75}$. It is not clear whether one should include these respondents or drop tem on the grounds that they did not fully understand the question.

${ }^{4}$ In 1992, individuals were asked to assess the chance they will "live to be 75 or more" on a scale of zero to 10 where zero means "absolutely no chance" and 10 means "absolutely certain." In 1994 and subsequent waves, individuals aged less than 65 were asked to assess the "percent chance" they will live to 75 or more. We use the 1992 data because it yields a larger sample. 82 percent of 1994 respondents provide probabilities that are multiples of ten.
} 
Research on the annuitization Social Security claiming, and other financial decisions A substantial literature (Mitchell, Poterba, Warshawasky, and Brown, 1999, Brown and Poterba, 2000, Sun and Webb, 2010) calculates the value of Social Security and other annuities to risk-averse households facing an uncertain lifespan, assuming plausible preference parameters. The literature shows that annuities have a value in excess of their money's worth, defined as the expected present value of the income stream, discounted by an interest rate and annual survival probabilities, divided by the premium paid. This is because households face an uncertain age of death. If they choose not to annuitize, they run the risk of outliving their wealth if they decumulate too rapidly or of foregoing valuable consumption opportunities if they decumulate too slowly.

The above papers assume that an individual's annual mortality risk equals that predicted by annuitant or population life tables. Brown (2003) and Sun and Webb (2010) show that although mortality rates vary significantly by socio-economic status, they have little effect on annuity valuation. Although the average household in high mortality groups faces a smaller chance of surviving to advanced old age, it will still want to restrict current consumption to safeguard against that possibility, should it choose not to annuitize.

Several researchers have undertaken empirical analyses of the Social Security claiming decision. Hurd, Smith, and Zissimpooulos (2004) find a small but significant relationship between subjective mortality beliefs and the age of claiming, as do Coile, Diamond, Gruber, and Jousten (2002). But in each case, the average delay is much less than 
theoretical calculations suggest is optimal.Gustman and Steinmeier (2005) estimate a structural model of the Social Security claiming decision and attribute the prevalence of early claiming to heterogeneity in rates of time preference. Benitez-Silva et al. (2006) also estimate a structural model and attribute the prevalence of early claiming to uncertainty as to whether scheduled benefits will be paid.

\section{What do households know or think they know about their mortality risk?}

We first compare 1992 subjective survival probabilities with subsequent mortality. In 1992, non-proxy HRS participants were asked to assess on a scale of zero to ten their chances of living to ages 75 and to age 85. In contrast to Hurd and McGarry (2002) who only had sufficient data to compare responses with mortality over a two-year period, we now possess sufficient data to compare survival probabilities with age 75 outcomes. Of the 5,378 men and 6,625 women non-proxy interviewees in the sample, we exclude those aged over 65 , leaving 4,932 and 6,571. Of these, 4,830 men and 6,440 women provided estimates of their probability of surviving to age 75 . Of these, 902 men and 815 women attained age 75 by the date of the 2008 interview (918 men and 839 women including people who were unable to assess their survival probability), and 481 men and 290 women died before reaching age 75 (495 men and 300 including those unable to assess their survival probability). ${ }^{5}$ We were unable to ascertain whether 94 men and 120 women had died prior to age $75 .{ }^{6}$

\footnotetext{
${ }^{5}$ When estimating regressions, we drop another 3 men and 21 women for whom we lack data on socioeconomic and health characteristics.

${ }^{6}$ We tested the sensitivity of our results to alternatively assuming that all the above had either died prior to age 75 or survived to that age and found it had little effect.
} 
We first investigate the information content of the above responses. Tables 1A (men) and 1B (women) report probit marginal effects for models in which the dependent variable takes the value one if the individual survives to age 75 ,and zero otherwise. ${ }^{7}$ The coefficient measures the impact of a one-unit change in the explanatory variable on the survival probability, holding all other characteristics constant at their means. Survival probabilities are expressed on a scale of zero to 100 . In the first specification, we include only the subjective survival probability as an explanatory variable. The coefficient is highly significant. But the relationship between subjective mortality beliefs and mortality outcomes is less than one for one. Among men and women, a one percent increase in self-assessed survival probability is associated with 0.3 and 0.2 percent increases in survival rates, respectively. Individuals are too willing to give extreme answers relative to their underlying survival probability. In reality, few individuals face close to a zero or 100 percent survival probability.

In the second specification, we instead include observable socio-economic and health variables. Among men, smoking, having a low household income, and reporting ever having been diagnosed with diabetes, cancer, lung or heart disease or stroke are associated with significant and substantial increases in mortality. High cognitive ability, as measured by a word recall test, is associated with a higher survival probability. ${ }^{8}$ Among women, diabetes, lung disease, high blood pressure, and having less than high school education are significant risk factors, while financial wealth has a

\footnotetext{
${ }^{7}$ We omit individuals whose survival status is unknown. These individuals do not report significantly different self-assessed survival probabilities.

${ }^{8} \mathrm{~A}$ one standard deviation change in the number of words recalled is associated with about a 6 percent change in survival probability.
} 
protective effect. The relationship between risk factors and mortality is similar to that found by Fong (2011).

In the third specification, we include both socio-economic and health variables, and selfassessed survival probabilities. The coefficients on the self-assessed survival probabilities are small and lacking in statistical significance, suggesting that individuals lack private information about their relative mortality risk. This finding has implications for annuity pricing. It suggests that adverse selection resulting from the use of private mortality information could be largely eliminated if annuities were medically

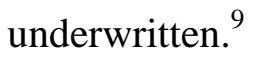

The first panel of Table 2 compares the self-assessed survival probabilities with the predictions of cohort life tables, the predictions of our econometric model, and the actual percent surviving. Unsurprisingly, the predictions of our econometric model are almost identical to the actual percent surviving. Men’s subjective mortality beliefs almost precisely equal the actual percent surviving. ${ }^{10}$ In contrast, at the mean, women underestimate their survival probabilities by 10 percent relative to the actual percent

\footnotetext{
${ }^{9}$ It would not eliminate adverse selection resulting from any correlation between longevity and aspects of preferences that influenced the annuitization decision, for example, if more risk-averse people had lower mortality and valued annuities more highly.

${ }^{10}$ The analysis excludes individuals whose survival status is unknown. At one extreme, one might treat all those whose survival status is unknown as having survived to age 75, in which case 65.3 percent of men and 76.9 percent of women would be classified as surviving. At the other extreme, one might treat all of them as having died, in which case, we would classify 59.8 percent of men and 69.4 percent of women as surviving. Under both alternative treatments, women underestimate their survival probabilities.
} 
surviving. Somewhat surprisingly, the actual percentages of men and women surviving are about three percentage points less than the predictions of life tables. ${ }^{11}$

The second and third panels of Table 2 compare self-assessed survival probabilities with the predictions of our econometric model. Among both men and women, the difference between the subjective survival probabilities of those who survive and the subjective survival probabilities of those who die before reaching age 75 is less than the difference in the survival probabilities predicted by our econometric model. Although individuals are prone to making excessively optimistic or pessimistic forecasts, they fail to make full use of information available to them when assessing their probability of surviving to age 75. ${ }^{12}$

The median survival probability predicted by our econometric model is higher than the mean, both for men and women, and both for survivors and those who die prior to attaining age 75 . The means are depressed by the predictions for a minority of individuals with very low survival probabilities. Among survivors, the median selfassessed survival probability is again higher than the mean. But the reverse is true among people who die before attaining age 75. The means are increased by a minority of individuals who report very high survival probabilities.

\footnotetext{
${ }^{11}$ Our expectation was that the percentages surviving would be somewhat higher than the predictions of life tables, due to the exclusion of those institutionalized at baseline.

${ }^{12}$ Using more explanatory variables, we could probably do an even better job of distinguishing between those who were going to survive and those who were going to die by age 75.
} 
We then investigate whether forecasting bias and error, relative to mortality outcomes, is associated with socio-economic status. We define bias as $p_{75}$ if the individual dies, and $p_{75}-1$ if he does not, where $p_{75}$ is the self-assessed probability of surviving to age 75 . The error is defined as $\left(p_{75}-1\right)^{2}$. We find that men underestimate the deleterious effects of current smoking and lung disease and women underestimate the effects of diabetes and lung disease but that there is no significant relationship between socio-economic status and forecasting bias. Although we find that women with less than a high school education make larger forecasting errors, there are few other statistically significant relationships between socio-economic and health status and forecasting error. ${ }^{13}$

Figures $1 \mathrm{~A}$ and $\mathrm{B}$ compare the distributions of subjective mortality beliefs with the distributions of the predictions of our econometric model, for men and women respectively. The $\mathrm{X}$ axes show survival probabilities, measured in percentages. The $\mathrm{Y}$ axes show the cumulative distributions of individuals. Extreme values are more prevalent among the self-reported data than among the predictions of our econometric model. Some individuals assign a zero probability to living to age 75 , whereas our econometric model tells us that even the most unhealthy have at least some chance of surviving to that age. Among women, the solid line is above the dotted line, over all except the top of the cumulative distribution of survival probabilities, indicating that they are more pessimistic than our econometric model would indicate is appropriate. The horizontal distance between the two lines measures the degree of understatement. This is higher at very low survival probabilities. But much of the mass is around the middle of the distribution.

\footnotetext{
${ }^{13}$ Results of these econometric models are available from the authors on request.
} 
We now investigate the nature and extent of focal point bias. To do so, we make use of follow-up questions that were first asked in the 2008 HRS wave. In 2008, individuals aged less than 65 were again asked to assess the probability that they would live to age 75. As in previous waves, a substantial proportion of individuals provided focal point estimates of zero, 50, 100 percent etc.

In contrast to previous waves, individuals were asked follow-up questions that were designed to test the degree of precision of their estimate. Those who answered 100 percent were asked the following question:

When you say 100 percent chance, do you mean that you are certain you will live to 75 or beyond, or do you mean you see a large enough chance that 100 is a good approximation?

Those who answered that it was an approximation were then asked:

If you think there is a large chance that you will live to 75 or beyond, please give your best estimate of what that chance is.

Those who answered zero percent were asked the following question:

When you say zero percent chance, do you mean that you see no chance at all are certain you will live to 75 or beyond, or do you mean you see a large enough chance that zero is a good approximation? 
Those who answered that it was an approximation were then asked:

If you think there is a small chance that you will live to 75 or beyond, please give your best estimate of what that chance is.

Individuals who answered10, 20, 25, 30, 40, 60, 75, 80, or 90 percent, and a random assignment of those who answered 50 percent were asked:

When you said x percent just now, did you mean this as an exact number or were you rounding or approximating?

Those who answered that it was an approximation were asked:

What range of numbers did you have in mind when you said $x$ percent?

The remainder of those answering 50 percent was asked:

Do you think that it is about equally likely that you will die before 75 as it is that you will live to 75 or beyond, or are you just unsure about the chances?

Figure 2 shows the response patterns. Of the 5,553 individuals aged under 65 who were asked the question, only 213 (3.8 percent) either refused to answer or said that they did not know, whereas 4,930(88.8 percent) gave answers that were multiples of 10 or 25 percent, and were therefore potential focal point responses. Of those who answered zero or 100 percent, 67 and 58 percent respectively stated that it was an exact number. Among those who answered some multiple of 10 or 25 percent, other than zero, 50, or 
100 percent, only 31.7 percent stated it was an exact number. Among those answering 50 percent, 38.8 percent stated that it was an exact number or that it was equally likely that they would survive to age 75 . People forecasting zero or 100 percent appear considerably more confident of their forecasting abilities than those forecasting other probabilities. It would appear that most individuals answering zero or 100 percent are not being affected by focal-point bias, but are providing what they believe to be a precise estimate. It is not clear whether they believe they have a zero probability of dying, or whether they believe the probability to be so small as to make 100 percent a close enough approximation.

Individuals who answered that their forecast was an approximation were generally able to provide a more precise estimate. Of those who initially answered zero, who stated it was an approximation, and who went on to give a more precise estimate, the average estimate was 24.4 percent, considerably higher than zero, suggesting that their original response was made in haste, and did not reflect their true beliefs. ${ }^{14}$ Of those providing an approximate probability of 100 percent, the average estimate was 84.3 percent, which again suggests that the original response did not reflect their true beliefs. The average range for individuals who answered 10, 20, 25, percent etc. was 18.4 percent. We interpret this as indicating that individuals attach a plausible degree of imprecision to their subjective mortality estimates.

\footnotetext{
${ }^{14}$ It is possible that participants may have interpreted the follow-up question as signifying that the interviewer regarded their original response as unreasonable.
} 
We then investigate whether there are differences between individuals who are able to provide subjective probabilities and those unable to do so, and whether there are also differences between those who say that their estimates are precise and those who say that they are approximations. Tables 3A and 3B show probit marginal effects for men and women, respectively. ${ }^{15}$ In the first model, the dependent variable takes the value one if the individual is unable to provide an estimate, zero otherwise. In the second models, the dependent variable takes the value one if the individual states that his response is approximately zero, and zero if he states that his response is precisely zero. In the third model, the dependent variable takes the value one if an individual answering 50 percent states that he is unsure whether he will survive and zero if he says it is about equally likely. In the fourth model, it takes the value one if the response is approximately 100 percent and zero if it is precisely 100 percent.

We find that among men, low financial wealth, a low level of mathematical ability, being a minority, and having been diagnosed with heart disease are associated with being unable to provide an estimate. ${ }^{16}$ Among women, those who are black or have less education are more likely to be unable to provide an estimate. Fewer explanatory variables attain conventional levels of significance in the remaining models, possibly reflecting smaller sample sizes. ${ }^{17}$ We therefore tentatively conclude that individuals who

\footnotetext{
${ }^{15}$ We analyze men and women separately because there are some significant differences between the coefficients on male and female explanatory variables.

${ }^{16}$ Although the coefficients are small, it should be borne in mind that only a small proportion of individuals answer that they are unable to state any probability. Some other variables are statistically significant and sometimes have an unexpected sign. For example, among women, engaging in any kind of physical activity is associated with an increase in the likelihood of being unable to estimate a survival probability. ${ }^{17}$ We decided not to pool the responses because factors that affect self-assessed survival probability may also influence the degree of precision the individual assigns to his estimate.
} 
state that their estimate is an exact number are not too different from those with the same subjective belief who admit to a degree of uncertainty.

We then investigate whether individuals exhibit excessive confidence in their ability to forecast their age of death. We first calculate the 2008 probability of surviving to age 85, conditional on reaching age 75 implied by the age 75 and 85 subjective survival probabilities and compare this with the predictions of life tables. A random sub-sample of participants was also asked to assess their probability of surviving to age 95. For this sub-sample, we calculate the probability of surviving to age 95, conditional on surviving to age 85 . Of the 5,567 individuals who were asked to assess their age 75 and 85 survival probabilities, we discard 14 who were older than 65 at the time of the interview, 213 who failed to answer the age 75 question, 661 who failed to answer the follow-up question, 102 who also failed to answer the age 85 question, and 358 for whom $p(85)>p(75)$, leaving 4,219. ${ }^{18}$ When calculating conditional probabilities, we drop an additional 159 individuals who answered that p(75) equals zero, leaving 4,060. Of the 806 under age 65 who answered the age 85 question and were asked and responded to the age 95 question, we discarded 78 who stated that their probability of surviving to age 85 was zero, and 68 who stated that $\mathrm{p}(95)>\mathrm{p}(85)$, leaving 660 .

\footnotetext{
${ }^{18}$ We discard observations where $\mathrm{p}(85)>\mathrm{p}(75)$, reasoning that these individuals do not understand the question. An alternative approach would be to code these individuals as believing that their conditional survival probability is 100 percent. This would increase the average conditional survival probability.
} 
Figure 3 compares the individuals' estimates of their probability of surviving to age 85, conditional on surviving to age 75 with the predictions of life tables. ${ }^{19}$ The mean selfassessed probabilities of surviving to age 85 , conditional on surviving to age 75 are 55.8 and 64.8 percent, respectively, compared with the 49.7 and 60.8 percent predictions of life tables for individuals drawn from the relevant birth cohorts. There is again considerable variation in self-assessed probabilities. The variation in self-assessed conditional survival probabilities seems implausibly large, likely reflecting measurement and reporting errors. ${ }^{20}$

A similar pattern emerges when we study the age 95 responses. The mean age 95 selfassessed survival probabilities are37.7 and 45.1 percent, respectively, compared with the 19.2 and 29.7 percent probabilities derived from life tables, reflecting the welldocumented tendency of individuals to overestimate the probability of surviving to older ages. $^{21}$ There is again considerable variation in self-assessed conditional survival probabilities.

We then recover annual survival probabilities from the $p_{75}$ and $p_{85}$ responses. To do this, we make use of the methodology described in Thatcher, Cheung, Horiuchi, and Robine (2010). They estimate a logistic mortality model of the following form:

\footnotetext{
${ }^{19}$ We construct probabilities of HRS participants surviving to ages 75 and 85 using Social Security Administration cohort life tables.

${ }^{20}$ If survival probabilities are reported with error, then differencing the probabilities will compound any reporting error.

${ }^{21}$ It is unclear whether this reflects a tendency to over-estimate the probability of occurrence of low probability outcomes, or that individuals simply over-estimate survival rates at older ages.
} 


$$
\mu(x)=\frac{a e^{b x}}{\left(1+a e^{b x}\right)}
$$

where $\mu(x)$ is the force of mortality at age $x$.

The logit function is defined by:

$\log i t(z)=\ln (z)-\ln (1-z)$

so that

$\log i t(\mu(x)+=\ln (a)+b x$

It follows that there is a linear relationship between $\log i t(\mu(x))$ and age. If we know the probabilities of surviving to two ages, we can recover $a$ and $b$ and calculate annual survival probabilities. This approach is only feasible where $p_{75}>p_{85}$ and where $p_{75} \neq 0, p_{75} \neq 100, p_{85} \neq 0, p_{85} \neq 100, p_{75}=p_{85}$. Of the sample of 4.577 with non-missing age 75 and age 85 estimates, there are 358 (7.8 percent) for whom $p_{85}>p_{75}, 159$ (3.5 percent) for whom both $p_{75}$ and $p_{85}$ equaled zero; 177 (3.9 percent) for whom both $p_{75}$ and $p_{85}$ equal 100 percent, and 399 (8.7 percent) for who both $p_{75}$ and $p_{85}$ equaled some other value. We therefore assume that the true beliefs of individuals answering zero or 100 percent are close to the above percentages. ${ }^{22}$ We also assume that when $p_{75}=p_{85}$, people have population average mortality adjusted by a scaling factor so that the probability of surviving to age 80 equals their age 75/85 response.

\footnotetext{
${ }^{22} \mathrm{We}$ assume that when individuals report that both $p_{75}$ and $p_{85}$ equal zero, the true underlying beliefs are five and one percent, and that when they both equal 100, the underlying beliefs are 99 and 95 percent. If only one of the two responses equals zero or 100 percent, we choose values that best fit the data.
} 
We construct individual level subjective mortality tables, and for each individual calculate self-assessed life expectancy and the standard deviation of the anticipated age of death, both conditional on attaining age 65. The blue circles in Figures $4 \mathrm{~A}$ and B show the frequency of the above variables for men and women, respectively, the areas of the circles being proportional to weighted frequency. ${ }^{23}$ The $\mathrm{X}$ axis shows remaining life expectancy, and the Y axis shows the standard deviation of age of death. The brown ovals show the predictions of life tables for individuals in various birth cohorts. There is little variation in life table predictions across birth cohorts, so the areas of the ovals are quite small. Some self-assessed life expectancies are to the left or right of the ovals, reflecting greater variation in subjective life expectancy than in the predictions of life tables. The majority of observations are below the ovals. For any given life expectancy, individuals are more certain of their age of death, relative to individuals whose annual mortality risk equals that predicted by life tables.

We recognize that the above calculations could be affected by our treatment of individuals answering zero or 100 percent. But our results are consistent with the hypothesis that individuals can predict their age of death with greater precision, relative to the predictions of life tables.

\section{How might subjective mortality beliefs affect the Social Security claiming decision?}

In this section, we calculate how variations in subjective mortality beliefs affect optimal Social Security claiming ages for married couple households. We first illustrate how

\footnotetext{
${ }^{23}$ To facilitate interpretation, we round observations to the nearest year.
} 
plausible variations in subjective mortality beliefs might affect the optimal claiming age and then calculate optimal claim ages for HRS households, given their reported beliefs.

For our calculations of the impact of plausible variations in subjective mortality beliefs, we follow Sun and Webb (2010) and consider a single-earner couple in which the husband is three years older than the wife. We assume the household has the following utility function:

$C_{t, m}=\frac{\left(C_{t, m}+\lambda C_{t, f}\right)^{\gamma}}{1-\gamma}$

where $\gamma$ is the coefficient of risk aversion and $\lambda$ measures the complementarity of consumption between husband and wife. The wife's utility function is symmetrical, and we assume that $\lambda=0.5$ and $\gamma=5$. The rates of interest and time preference are assumed to be three percent.

To separate the retirement from the Social Security claiming decision, we assume the household has an amount of financial assets equal to the expected present value of its Social Security wealth. In each period, the household decides how much to consume, whether the husband should claim Social Security retired worker benefit, and whether, if the husband has claimed retired worker benefit, the wife should claim spousal benefit. The retired worker benefit is subject to an actuarial reduction of up to 25 percent if the husband claims at age 62, and an actuarial increase of up to 32 percent if he delays until 
age 70. The spousal benefit can only be claimed once the husband has claimed the retired worker benefit, and it equals 50 percent of the benefits the husband would receive if he claimed at age 66. It is subject to an actuarial reduction of up to 30 percent if claimed at age 62. There is no actuarial increase in the event of delayed claiming. On the death of the husband, the spousal benefit is replaced by a survivor benefit of 100 percent of the husband's benefit.

We calculate the optimal combination of claim ages, the combination that maximizes the household's expected utility. We also calculate Social Security Equivalent Income (SSEI), the factor by which the Social Security income of a household claiming at a suboptimal combination of ages must be multiplied so that it is indifferent between claiming at the sub-optimal and optimal ages.

A household that has greater life expectancy will value the Social Security annuity more highly. Holding life expectancy constant, a household that is more uncertain of its age of death will also value the Social Security annuity more highly because if it does not annuitize, it will optimally plan to set aside greater wealth for consumption in the event it survives to advanced old age.

Table 4 shows the results of calculations in which we first report optimal claiming ages and SSEI for households with population average mortality. ${ }^{24}$ The optimal claiming ages are 69 for the husband and 66 for the wife. Age 62 SSEI is 1.161, in other words, if they are forced to claim at age 62, they would require a 16.1 percent increase in age 62

\footnotetext{
${ }^{24}$ We assume that both husband was born in 1949 and that the wife is three years younger.
} 
benefits to be as well-off in expected utility terms. Male and female life expectancy at age 62 are 20 and 26 years, respectively.

To illustrate the effect of plausible variations in subjective mortality beliefs, we first increase and then decrease life expectancy by 20 percent. For men, a 20 percent change in age-65 life expectancy approximates to four years and, for women, to five years. To put these in context, Brown, Liebman, and Pollet (2002) estimate male and female differences in life expectancy at age 67 between whites with a college education and blacks with less than a high school education of 3.4 and 2.7 years, respectively. These changes have no effect on the optimal combination of claim ages. Decreasing life expectancy by 20 percent reduces SSEI by 2.8 percentage points, and increasing it by 20 percent increases SSEI by 2.9 percentage points. Even high mortality households face some probability of surviving to advanced ages, and therefore value the additional longevity insurance acquired as a result of delayed claiming of Social Security benefits.

Fong (2011) estimates a Gompertz proportional hazard model and finds that health and socio-economic status result in significant percentage changes in mortality rates. For example, and depending on model specification, minorities have mortality rates that are 12 to 18 percent higher, while having 12 or more years of schooling is associated with a 6 to 27 percent reduction in mortality. ${ }^{25}$ To estimate the impact of proportional increases

\footnotetext{
${ }^{25}$ Fong (2011) finds that as she increases the number of health and socio-economic variables, gamma - the annual percentage increase in mortality - increases from 6.3 to 8.1 percent. In correspondence, she informs us that this increase is statistically significant at the one percent level. As gamma increases, uncertainty as to the age of death decreases, reducing the value of annuitization. It would be interesting to know whether gamma varies with socio-economic status. But the HRS dataset is not large enough to permit estimation of models with interaction terms of this type.
} 
and decreases in mortality rates on the optimal combination of Social Security claim ages, we estimate a model in which annual mortality rates increase or decrease by 20 percent. We find that changes of this magnitude have no effect on the optimal Social Security claim age.

We then increase and decrease the variance of the age of death by 20 percent, holding life expectancy constant. A 20 percent increase in variance increases the interquartile range of male and female ages of death by two and three years respectively. A 20 percent decrease reduces the interquartile range by two years for both men and women. But these changes have almost no effect on SSEI, changing it from 16.2 percent to 16.9 and 15.5 percent, respectively, and again have no effect on the optimal combination of claim ages.

Finally, we calculate optimal claiming ages assuming that both husband and wife have both life expectancy and standard deviation of life expectancy that lie at the $10^{\text {th }}$ or 25 percentiles of the respective distributions. ${ }^{26}$ These are individuals who are fairly confident, but not certain, that they will not survive to advanced old age. At the $10^{\text {th }}$ percentile, it becomes optimal to claim Social Security at somewhat younger ages - age 65 for the husband and age 62 for the wife.

We conclude that for plausible preference parameters, observed variations in subjective mortality beliefs have only very small effects on optimal claiming behavior. For

\footnotetext{
${ }^{26}$ There is less than perfect correlation between life expectancy and the standard deviation of life expectancy. Among men and women, 60 and 61 percent have both life expectancy and the standard deviation of age of death above the $25^{\text {th }}$ percentile, and among both men and women, 82 percent have both life expectancy and standard deviation of age of death above the $10^{\text {th }}$ percentile. There is also substantial, but less than perfect correlation between the percentile ranking of spouses' beliefs.
} 
claiming at age 62 to be optimal, households that were not liquidity constrained would require preferences or subjective mortality beliefs that departed very substantially from those outlined above. Specifically, they would have to substantially over-estimate their mortality risk and be highly confident of their ability to forecast their age of death, or have very high rates of time preference that would be difficult to reconcile with the accumulation of significant financial wealth.

\section{Conclusions}

Economists and investment advisers generally regard the risk of outliving one's wealth as one of the most significant financial risks faced by most retired households. But Sondergeld, Drinkwater, and Jamison (2002) report that only 16 percent of retired households expressed "major concern" about its potential impact on their standard of living.

Annuities provide insurance against outliving one's wealth. The value of this longevity insurance depends not only on life expectancy but also on the degree of uncertainty surrounding the individual's age of death. Theoretical calculations of the value of annuitization assume that individuals have population average annual mortality risk. But this assumption may not be realistic. Individuals know whether they are more or less likely to survive to specified ages, relative to the predictions of life tables. Simply knowing that one's annual mortality risk is higher or lower than average has little effect on the interquartile survival range. But individuals may possess, or think they possess 
information that allows them be confident of their ability to forecast their age of death, relative to forecasts derived from an analysis of life table data.

Using HRS data, we show that women, but not men, are pessimistic about their chances of surviving to age 75 , and that, relative to the predictions of life tables, individuals are considerably more confident of their ability to forecast their age of death. This reduces the benefit obtained from delayed claiming of Social Security benefits. But substituting the above beliefs for the assumption that individuals have population average mortality has only a small effect on the optimal claiming age and the returns to delayed claiming of benefits. Our calculations of optimal behavior confirm the findings of empirical research, namely that subjective mortality beliefs have only a small effect on claiming behavior. 


\section{References}

Benitez-Silva, Hugo, Debra S. Dwyer, Frank Heiland, and Warren C. Sanderson. 2006.

"Retirement and Social Security Reform Expectations: A Solution to the New Early Retirement Puzzle" Stony Brook University Department of Economics Working Paper 06-05.

Brown, Jeffrey R. and James M. Poterba. 2000. "Joint Life Annuities and the Demand for Annuities by Married Couples,” Journal of Risk and Insurance, 67(4): pp. 527 - 553.

Brown, Jeffrey R. 2002. "Differential Mortality and the Value of Individual Account Retirement Annuities” In The Distributional Aspects of Social Security and Social Security ReformEds Feldstein, Martin and Jeffrey B. Liebman University of Chicago Press, Chicago IL. Pages 401-446

Brown, Jeffrey R., Jeffrey B. Liebman, and Joshua Pollet 2002. “Estimating Life Tables that Reflect Socioeconomic Differences in Mortality” In The Distributional Aspects of Social Security and Social Security Reform Eds Feldstein, Martin and Jeffrey B. Liebman University of Chicago Press, Chicago IL. Pages 447-57

Brown, Jeffrey R. 2003. "Redistribution and Insurance: Mandatory Annuitization with Mortality Heterogeneity” Journal of Risk and Insurance Vol. 70 No. 1. Pages 17-41

Coile, Courtney, Peter Diamond, Jonathan Gruber, and Alain Jousten. 2002. "Delays in Claiming Social Security Benefits” Journal of Public Economics 84. Pages 357-385.

Elder, Todd E. 2007. "Subjective Survival Probabilities in the Health and Retirement Study: Systematic Biases and Predictive Validity” Michigan Retirement Research Center Working Paper 2007-159.

Fong, Joelle H.Y. 2011. "Beyond Age and Sex: Enhancing Annuity Pricing” Pension Research Council Working Paper PRC WP 2011-07.

Gan, Li, Michael D.Hurd, and Daniel McFadden. 2005. “Individual Subjective Survival Curves” In Analyses in the Economics of Aging Ed. Wise, David A. University of Chicago Press, Chicago. Pages 377-402.

Gustman, Alan L., and Thomas L. Steinmeier. 2005. “The Social Security Early Entitlement Age in a Structural Model of Retirement and Wealth. Journal of Public Economics. Vol. 29 No. 2-3. Pages 441-63

Hurd, Michael D., and Kathleen McGarry. 1995. "Evaluation of Subjective Probability Distributions in the Health and Retirement Study" Journal of Human Resources Vol. 30. Supplement. Pages S268-92.

Hurd, Michael D., and Kathleen McGarry. 2002. “The Predictive Validity of Subjective Probabilities of Survival” The Economic Journal. Vol. 112.Pages 966-985. 
Hurd, Michael D., James P. Smith and Julie M. Zissimopoulos. 2004. "The Effects of Subjective Survival on Retirement and Social Security Claiming” Journal of Applied Econometrics. Vol. 19 No. 6 Special Issue Pages 761-75.

Mitchell, Olivia S., James Poterba, Mark J. Warshawsky and Jeffrey R. Brown. 1999. "New Evidence on the Money's Worth of Individual Annuities," American Economic Review, Vol. 89 No. 5, pp.1299-1318.

Sondergeld, Eric T., Matthew Drinkwater, and Kent Jamison. 2002. "Retirement Risks: How They Are Viewed and Managed” Windsor CT. LIMRA International.

Sun, Wei, and Anthony Webb. 2010. "How Much do Households Really Lose By Claiming Social Security At Age 62" Center for Retirement Research at Boston College Working Paper 2009-11, Journal of Risk and Insurance, forthcoming (with Wei Sun)

Thatcher, Roger A., Siu Lan Cheung, Shiro Horiuchi, and Jean-Marie Robine. 2010. "The Compression of Deaths Above the Mode" Demographic Research. Vol. 22 Article 17.Pages 505-538. 
Table 1A: Predictors of survival to age 75 - Males

Self-assessed probability of living to age 75 Doesn't know survival probability

Log household income

Log financial wealth

Age

Married

Race:

Black

Hispanic

Education:

Less than high school

Some college

Smoke ever

Smoke now

Drink ever

Never do vigorous physical activity

Never do light physical activity

Ever been diagnosed with:

High blood pressure

Diabetes

Cancer

Lung Disease

Heart Disease

Stroke

Arthritis

Obese

Number of words recalled-immedialy

Number of words recalled-delayed

$\mathrm{N}$ unweighted

\begin{tabular}{|c|c|c|c|c|c|}
\hline $\begin{array}{l}\text { Marginal } \\
\text { effect }\end{array}$ & $\begin{array}{l}\text { Std } \\
\text { error }\end{array}$ & $\begin{array}{l}\text { Marginal } \\
\text { effect }\end{array}$ & $\begin{array}{l}\text { Std } \\
\text { error }\end{array}$ & $\begin{array}{l}\text { Marginal } \\
\text { effect }\end{array}$ & $\begin{array}{l}\text { Std } \\
\text { error }\end{array}$ \\
\hline $0.003 * * *$ & 0.001 & & & 0.001 & 0.001 \\
\hline$-0.228 *$ & 0.124 & & & -0.166 & 0.116 \\
\hline $0.031 * *$ & 0.013 & $0.032 * *$ & 0.013 & $0.031 * *$ & 0.013 \\
\hline-0.001 & 0.003 & -0.001 & 0.003 & -0.001 & 0.003 \\
\hline $0.112 * * *$ & 0.021 & $0.112 * * *$ & 0.021 & $0.112 * * *$ & 0.021 \\
\hline 0.066 & 0.049 & 0.074 & 0.049 & 0.066 & 0.049 \\
\hline 0.008 & 0.057 & 0.008 & 0.056 & 0.008 & 0.057 \\
\hline 0.073 & 0.065 & 0.071 & 0.065 & 0.073 & 0.065 \\
\hline 0.021 & 0.047 & 0.019 & 0.047 & 0.021 & 0.047 \\
\hline-0.066 & 0.046 & -0.064 & 0.046 & -0.066 & 0.046 \\
\hline-0.061 & 0.045 & -0.069 & 0.045 & -0.061 & 0.045 \\
\hline$-0.192 * * *$ & 0.048 & $-0.196 * * *$ & 0.048 & $-0.192 * * *$ & 0.048 \\
\hline $0.098 * *$ & 0.042 & $0.102 * *$ & 0.042 & $0.098 * *$ & 0.042 \\
\hline 0.041 & 0.049 & 0.043 & 0.049 & 0.041 & 0.049 \\
\hline 0.005 & 0.037 & 0.008 & 0.037 & 0.005 & 0.037 \\
\hline-0.046 & 0.040 & -0.046 & 0.040 & -0.046 & 0.040 \\
\hline$-0.174 * * *$ & 0.057 & $-0.176 * * *$ & 0.056 & $-0.174 * * *$ & 0.057 \\
\hline$-0.234 * * *$ & 0.087 & $-0.244 * * *$ & 0.088 & $-0.234 * * *$ & 0.087 \\
\hline$-0.331 * * *$ & 0.065 & $-0.341 * * *$ & 0.065 & $-0.331 * * *$ & 0.065 \\
\hline$-0.198 * * *$ & 0.052 & $-0.208 * * *$ & 0.052 & $-0.198 * * *$ & 0.052 \\
\hline$-0.283 * * *$ & 0.103 & $-0.290 * * *$ & 0.101 & $-0.283 * * *$ & 0.103 \\
\hline-0.030 & 0.039 & -0.031 & 0.039 & -0.030 & 0.039 \\
\hline-0.075 & 0.050 & -0.077 & 0.050 & -0.075 & 0.050 \\
\hline $0.024 * *$ & 0.010 & $0.023 * *$ & 0.010 & $0.024 * *$ & 0.010 \\
\hline-0.012 & 0.010 & -0.011 & 0.010 & -0.012 & 0.010 \\
\hline 1413 & & 1410 & & 1410 & \\
\hline 921 & & 920 & & 920 & \\
\hline
\end{tabular}

Notes: HRS sample weights. One, two, or three stars indicate that the coefficient is significantly different from zero at the 10, 5, or 1 percent level of significance, respectively. 
Table 1B: Predictors of survival to age 75 - Females

\begin{tabular}{|c|c|c|c|c|c|c|}
\hline & $\begin{array}{l}\text { Marginal } \\
\text { effect }\end{array}$ & $\begin{array}{l}\text { Std } \\
\text { error }\end{array}$ & $\begin{array}{l}\text { Marginal } \\
\text { effect }\end{array}$ & $\begin{array}{l}\text { Std } \\
\text { error }\end{array}$ & $\begin{array}{l}\text { Marginal } \\
\text { effect }\end{array}$ & $\begin{array}{l}\text { Std } \\
\text { error }\end{array}$ \\
\hline Self-assessed probability of living to age 75 & $0.002 * * *$ & 0.001 & & & 0.001 & 0.001 \\
\hline Doesn't know survival probability & -0.048 & 0.096 & & & 0.039 & 0.087 \\
\hline Log household income & & & -0.002 & 0.008 & -0.002 & 0.009 \\
\hline Log financial wealth & & & $0.007 * * *$ & 0.002 & $0.007 * * *$ & 0.002 \\
\hline Age & & & $0.076 * * *$ & 0.018 & $0.076 * * *$ & 0.018 \\
\hline Married & & & 0.031 & 0.034 & 0.031 & 0.034 \\
\hline \multicolumn{7}{|l|}{ Race: } \\
\hline Black & & & 0.027 & 0.039 & 0.025 & 0.039 \\
\hline Hispanic & & & 0.023 & 0.050 & 0.022 & 0.050 \\
\hline \multicolumn{7}{|l|}{ Education: } \\
\hline Less than high school & & & $-0.083 * *$ & 0.041 & $-0.085 * *$ & 0.041 \\
\hline Some college & & & -0.032 & 0.039 & -0.034 & 0.039 \\
\hline Smoke ever & & & -0.048 & 0.034 & -0.048 & 0.034 \\
\hline Smoke now & & & $-0.075 *$ & 0.045 & $-0.075 *$ & 0.045 \\
\hline Drink ever & & & 0.043 & 0.032 & 0.040 & 0.032 \\
\hline Never do vigorous physical activity & & & 0.026 & 0.039 & 0.026 & 0.039 \\
\hline Never do light physical activity & & & $0.061 * *$ & 0.030 & $0.056 *$ & 0.030 \\
\hline \multicolumn{7}{|l|}{ Ever been diagnosed with: } \\
\hline High blood pressure & & & $-0.085 * * *$ & 0.032 & $-0.083 * * *$ & 0.033 \\
\hline Diabetes & & & $-0.276 * * *$ & 0.058 & $-0.272 * * *$ & 0.058 \\
\hline Cancer & & & -0.102 & 0.071 & -0.099 & 0.071 \\
\hline Lung Disease & & & $-0.319 * * *$ & 0.081 & $-0.313 * * *$ & 0.082 \\
\hline Heart Disease & & & -0.072 & 0.055 & -0.069 & 0.055 \\
\hline Stroke & & & -0.019 & 0.095 & -0.025 & 0.098 \\
\hline Arthritis & & & 0.008 & 0.029 & 0.008 & 0.029 \\
\hline Obese & & & 0.042 & 0.032 & 0.042 & 0.032 \\
\hline Number of words recalled-immedialy & & & 0.007 & 0.009 & 0.007 & 0.009 \\
\hline Number of words recalled-delayed & & & 0.003 & 0.008 & 0.004 & 0.008 \\
\hline & 1139 & & 1118 & & 1118 & \\
\hline $\mathrm{N}$ & 1021 & & 1020 & & 1020 & \\
\hline
\end{tabular}

Notes: HRS sample weights. One, two, or three stars indicate that the coefficient is significantly different from zero at the 10, 5, or 1 percent level of significance, respectively. 
Table 2: Comparison of self-assessed with actual survival probabilities

\begin{tabular}{|c|c|c|c|c|}
\hline & Men & & Women & \\
\hline & Mean & Median & Mean & Median \\
\hline Self-assessed survival probability & 63.35 & 70.00 & 64.61 & 70.00 \\
\hline Predictions of SSA cohort mortality tables & 66.55 & 66.64 & 77.72 & 77.75 \\
\hline Predictions of econometric model & 63.06 & 67.55 & 75.18 & 81.91 \\
\hline Actual percent surviving & 63.33 & & 75.03 & \\
\hline & & Survivors & & \\
\hline & Men & & Womem & \\
\hline Self-assessed survival probability & 67.18 & 70.00 & 66.83 & 70.00 \\
\hline Predictions of econometric model & 71.33 & 74.87 & 80.04 & 84.60 \\
\hline & Those & who do not $\mathrm{s}$ & urvive & \\
\hline & Men & & Womem & \\
\hline Self-assessed survival probability & 56.73 & 50.00 & 57.94 & 50.00 \\
\hline Predictions of econometric model & 48.79 & 52.55 & 60.58 & 64.64 \\
\hline
\end{tabular}

Note: SSA cohort mortality tables are for men and women in the appropriate birth cohorts. 
Table 3A: Probit marginal effects - unable to predict or unsure of age 75 survival probability - Males

\begin{tabular}{|c|c|c|c|c|c|c|c|c|}
\hline & \multicolumn{2}{|c|}{ Unable to state any } & \multicolumn{2}{|c|}{$\begin{array}{l}\text { Answers zero } \\
\text { Is an approximation }\end{array}$} & \multicolumn{2}{|l|}{$\begin{array}{l}\text { Answers 50\% } \\
\text { Is unsure }\end{array}$} & \multicolumn{2}{|c|}{$\begin{array}{l}\text { Answers } 100 \% \\
\text { Is an approximation }\end{array}$} \\
\hline & $\begin{array}{l}\text { Marginal } \\
\text { effect }\end{array}$ & $\begin{array}{l}\text { Standard } \\
\text { error }\end{array}$ & $\begin{array}{l}\text { Marginal } \\
\text { effect }\end{array}$ & $\begin{array}{l}\text { Standard } \\
\text { error }\end{array}$ & $\begin{array}{l}\text { Marginal } \\
\text { effect }\end{array}$ & $\begin{array}{l}\text { Standard } \\
\text { error }\end{array}$ & $\begin{array}{l}\text { Marginal } \\
\text { effect }\end{array}$ & $\begin{array}{l}\text { Standard } \\
\text { error }\end{array}$ \\
\hline Math Score scale of 0 to 4 & $-0.005 * *$ & 0.003 & 0.041 & 0.044 & $-0.062 *$ & 0.035 & -0.002 & 0.031 \\
\hline Math Score missing & 0.002 & 0.010 & $-0.232 * *$ & 0.054 & 0.226 & 0.134 & -0.103 & 0.141 \\
\hline Log household income & 0.001 & 0.002 & $0.062 * * *$ & 0.022 & -0.072 & 0.051 & -0.039 & 0.037 \\
\hline Log financial wealth & $-0.001 * *$ & 0.000 & -0.013 & 0.008 & -0.006 & 0.006 & $0.008 *$ & 0.005 \\
\hline Age & $0.002 *$ & 0.001 & 0.021 & 0.019 & -0.003 & 0.013 & 0.007 & 0.013 \\
\hline \multicolumn{9}{|l|}{ Male } \\
\hline Married & -0.006 & 0.007 & 0.158 & 0.098 & $0.165 *$ & 0.097 & -0.043 & 0.089 \\
\hline \multicolumn{9}{|l|}{ Race: } \\
\hline Black & $0.031 * * *$ & 0.014 & -0.006 & 0.185 & -0.038 & 0.126 & -0.013 & 0.091 \\
\hline Hispanic & $0.036 * * *$ & 0.018 & $0.510 * * *$ & 0.169 & -0.166 & 0.145 & 0.062 & 0.154 \\
\hline \multicolumn{9}{|l|}{ Education: } \\
\hline Less than high school & 0.003 & 0.010 & -0.164 & 0.099 & $-0.355 * *$ & 0.126 & 0.069 & 0.134 \\
\hline Some college & 0.001 & 0.006 & -0.183 & 0.110 & -0.142 & 0.090 & 0.096 & 0.091 \\
\hline Smoke ever & 0.004 & 0.006 & 0.074 & 0.112 & $-0.207 * *$ & 0.092 & $-0.141 *$ & 0.077 \\
\hline Smoke now & 0.000 & 0.006 & -0.161 & 0.130 & 0.104 & 0.093 & 0.043 & 0.109 \\
\hline Drink ever & 0.005 & 0.006 & -0.054 & 0.142 & -0.095 & 0.091 & -0.085 & 0.077 \\
\hline Never do vigorous physical activity & 0.002 & 0.009 & 0.139 & 0.137 & -0.042 & 0.123 & -0.122 & 0.130 \\
\hline Never do moderate physical activity & -0.003 & 0.008 & -0.011 & 0.123 & -0.028 & 0.151 & 0.091 & 0.177 \\
\hline Never do light physical activity & $-0.012 * *$ & 0.007 & 0.028 & 0.096 & 0.059 & 0.081 & -0.094 & 0.077 \\
\hline \multicolumn{9}{|l|}{ Ever been diagnosed with: } \\
\hline High blood pressure & -0.009 & 0.006 & $-0.281 * *$ & 0.154 & -0.014 & 0.088 & 0.008 & 0.077 \\
\hline Diabetes & -0.007 & 0.006 & 0.025 & 0.118 & $0.169 *$ & 0.094 & $0.187 *$ & 0.104 \\
\hline Cancer & $-0.015 *$ & 0.005 & 0.354 & 0.252 & -0.204 & 0.146 & $-0.247 *$ & 0.098 \\
\hline Lung Disease & -0.001 & 0.010 & -0.030 & 0.149 & -0.082 & 0.138 & 0.167 & 0.151 \\
\hline Heart Disease & $0.019 * *$ & 0.011 & -0.111 & 0.096 & 0.098 & 0.085 & -0.030 & 0.105 \\
\hline Stroke & 0.001 & 0.011 & -0.146 & 0.095 & -0.152 & 0.165 & 0.049 & 0.197 \\
\hline Arthritis & 0.000 & 0.005 & -0.107 & 0.125 & $-0.137 *$ & 0.082 & $0.196 * *$ & 0.077 \\
\hline Obese & 0.008 & 0.006 & $-0.189 *$ & 0.097 & 0.069 & 0.084 & $0.143 *$ & 0.079 \\
\hline Number of words recalled-immedialy & -0.004 & 0.003 & $-0.118 *$ & 0.065 & $-0.092 * *$ & 0.045 & 0.006 & 0.034 \\
\hline Number of words recalled-delayed & 0.003 & 0.002 & $0.083 *$ & 0.047 & 0.042 & 0.038 & -0.020 & 0.027 \\
\hline $\mathrm{N}$ unweighted & 2053 & & 97 & & 233 & & 284 & \\
\hline $\mathrm{N}$ & 1858 & & 84 & & 213 & & 256 & \\
\hline
\end{tabular}


Table 3B: Probit marginal effects - unable to predict or unsure of age 75 survival probability - Females

\begin{tabular}{|c|c|c|c|c|c|c|c|c|}
\hline & \multicolumn{2}{|l|}{ Unable to state any } & \multicolumn{2}{|c|}{$\begin{array}{l}\text { Answers zero } \\
\text { Is an approximation }\end{array}$} & \multicolumn{2}{|l|}{$\begin{array}{l}\text { Answers 50\% } \\
\text { Is unsure }\end{array}$} & \multicolumn{2}{|c|}{$\begin{array}{l}\text { Answers } 100 \% \\
\text { Is an approximation }\end{array}$} \\
\hline & $\begin{array}{l}\text { Marginal } \\
\text { effect }\end{array}$ & $\begin{array}{l}\text { Standard } \\
\text { error }\end{array}$ & $\begin{array}{l}\text { Marginal } \\
\text { effect }\end{array}$ & $\begin{array}{l}\text { Standard } \\
\text { error }\end{array}$ & $\begin{array}{l}\text { Marginal } \\
\text { effect }\end{array}$ & $\begin{array}{l}\text { Standard } \\
\text { error }\end{array}$ & $\begin{array}{l}\text { Marginal } \\
\text { effect }\end{array}$ & $\begin{array}{l}\text { Standard } \\
\text { error }\end{array}$ \\
\hline Math Score scale of 0 to 4 & 0.000 & 0.003 & -0.043 & 0.067 & 0.018 & 0.032 & 0.029 & 0.026 \\
\hline Math Score missing & 0.018 & 0.021 & -0.139 & 0.200 & 0.127 & 0.217 & 0.169 & 0.170 \\
\hline Log household income & $-0.002 * *$ & 0.001 & 0.138 & 0.092 & 0.031 & 0.022 & 0.015 & 0.019 \\
\hline Log financial wealth & 0.000 & 0.000 & 0.000 & 0.007 & -0.005 & 0.005 & -0.001 & 0.004 \\
\hline Age & -0.001 & 0.001 & $0.035 *$ & 0.021 & 0.019 & 0.012 & 0.013 & 0.010 \\
\hline \multicolumn{9}{|l|}{ Male } \\
\hline Married & 0.008 & 0.006 & 0.204 & 0.157 & $-0.242 * * *$ & 0.075 & 0.077 & 0.062 \\
\hline \multicolumn{9}{|l|}{ Race: } \\
\hline Black & $0.025 * *$ & 0.013 & 0.279 & 0.184 & 0.020 & 0.114 & 0.041 & 0.073 \\
\hline Hispanic & 0.002 & 0.009 & -0.004 & 0.165 & 0.027 & 0.125 & -0.090 & 0.096 \\
\hline \multicolumn{9}{|l|}{ Education: } \\
\hline Less than high school & $0.028 * * *$ & 0.015 & -0.185 & 0.107 & 0.071 & 0.123 & $0.255 * * *$ & 0.094 \\
\hline Some college & $-0.013 * *$ & 0.005 & $0.322 * *$ & 0.192 & $-0.130 *$ & 0.076 & -0.007 & 0.064 \\
\hline Smoke ever & 0.004 & 0.006 & 0.087 & 0.151 & -0.057 & 0.080 & 0.009 & 0.060 \\
\hline Smoke now & $-0.016 * * *$ & 0.005 & 0.013 & 0.183 & 0.088 & 0.098 & 0.025 & 0.090 \\
\hline Drink ever & -0.003 & 0.005 & -0.109 & 0.155 & $-0.175 * *$ & 0.075 & $0.104 *$ & 0.059 \\
\hline Never do vigorous physical activity & $0.020 * *$ & 0.011 & -0.028 & 0.163 & 0.068 & 0.103 & 0.005 & 0.093 \\
\hline Never do moderate physical activity & $-0.016 * *$ & 0.005 & -0.110 & 0.174 & -0.047 & 0.192 & 0.123 & 0.200 \\
\hline Never do light physical activity & $-0.018 * * *$ & 0.006 & -0.111 & 0.132 & -0.043 & 0.073 & -0.001 & 0.058 \\
\hline \multicolumn{9}{|l|}{ Ever been diagnosed with: } \\
\hline High blood pressure & 0.005 & 0.006 & $-0.324 * *$ & 0.152 & -0.086 & 0.080 & 0.009 & 0.059 \\
\hline Diabetes & 0.008 & 0.007 & 0.112 & 0.138 & 0.081 & 0.095 & 0.037 & 0.081 \\
\hline Cancer & 0.010 & 0.010 & 0.279 & 0.195 & 0.110 & 0.102 & $0.162 *$ & 0.098 \\
\hline Lung Disease & $0.023 * *$ & 0.014 & 0.213 & 0.157 & -0.155 & 0.102 & -0.001 & 0.150 \\
\hline Heart Disease & -0.009 & 0.006 & 0.229 & 0.186 & -0.055 & 0.087 & 0.004 & 0.099 \\
\hline Stroke & 0.005 & 0.016 & 0.281 & 0.267 & $0.336 * *$ & 0.115 & $0.338 * *$ & 0.148 \\
\hline Arthritis & 0.003 & 0.005 & $-0.679 * * *$ & 0.158 & -0.089 & 0.075 & -0.015 & 0.057 \\
\hline Obese & $-0.013 * * *$ & 0.005 & 0.190 & 0.125 & -0.040 & 0.075 & 0.057 & 0.064 \\
\hline Number of words recalled-immedialy & 0.000 & 0.003 & -0.071 & 0.045 & $-0.085 * *$ & 0.040 & -0.003 & 0.027 \\
\hline Number of words recalled-delayed & -0.003 & 0.003 & $0.064 *$ & 0.037 & 0.023 & 0.033 & -0.011 & 0.022 \\
\hline $\mathrm{N}$ unweighted & 3344 & & 117 & & 360 & & 556 & \\
\hline $\mathrm{N}$ & 2617 & & 86 & & 288 & & 445 & \\
\hline
\end{tabular}

Table 4: Impact of Mortality Beliefs on Optimal Claim Age

\begin{tabular}{|c|c|c|c|c|c|c|c|c|c|}
\hline \multirow[b]{3}{*}{ Baseline } & \multicolumn{2}{|c|}{ Life Expectancy } & \multicolumn{2}{|c|}{$\begin{array}{l}\text { Interquartile survival } \\
\text { range }\end{array}$} & \multicolumn{2}{|l|}{$\begin{array}{l}\text { Interquartile } \\
\text { survival range }\end{array}$} & \multicolumn{2}{|c|}{ Optimal claim ages } & \multirow{2}{*}{$\begin{array}{l}\text { Social Security } \\
\text { Equivalent } \\
\text { Income }\end{array}$} \\
\hline & Men & Women & Men & & Women & & Men & Women & \\
\hline & 82 & 85 & 75 & 89 & 78 & 93 & 69 & 66 & 1.161 \\
\hline Annual mortality rate $+20 \%$ & 80 & 83 & 73 & 87 & 76 & 91 & 69 & 66 & 1.147 \\
\hline Annual mortality rate $-20 \%$ & 84 & 87 & 77 & 91 & 80 & 95 & 69 & 66 & 1.176 \\
\hline Life expectancy $+20 \%$ & 86 & 90 & 79 & 93 & 84 & 99 & 69 & 66 & 1.190 \\
\hline Life expectancy - $20 \%$ & 78 & 80 & 70 & 85 & 72 & 88 & 69 & 66 & 1.133 \\
\hline Variance of age of death $+20 \%$ & 82 & 85 & 74 & 90 & 77 & 94 & 69 & 66 & 1.169 \\
\hline Variance of age of death - $20 \%$ & 82 & 85 & 76 & 88 & 79 & 92 & 69 & 66 & 1.155 \\
\hline 25 th percentile & 80 & 79 & 76 & 84 & 75 & 83 & 68 & 65 & 1.073 \\
\hline 10th percentile & 73 & 74 & 70 & 77 & 71 & 77 & 65 & 62 & 1.003 \\
\hline Annual mortality rate $+50 \%$ & 79 & 82 & 72 & 85 & 74 & 89 & 69 & 66 & 1.127 \\
\hline Annual mortality rate $+100 \%$ & 76 & 79 & 70 & 82 & 72 & 86 & 69 & 66 & 1.098 \\
\hline
\end{tabular}


Figure 1A: Predicted and Self-Assessed Probability of Living to Age 75 -

Males

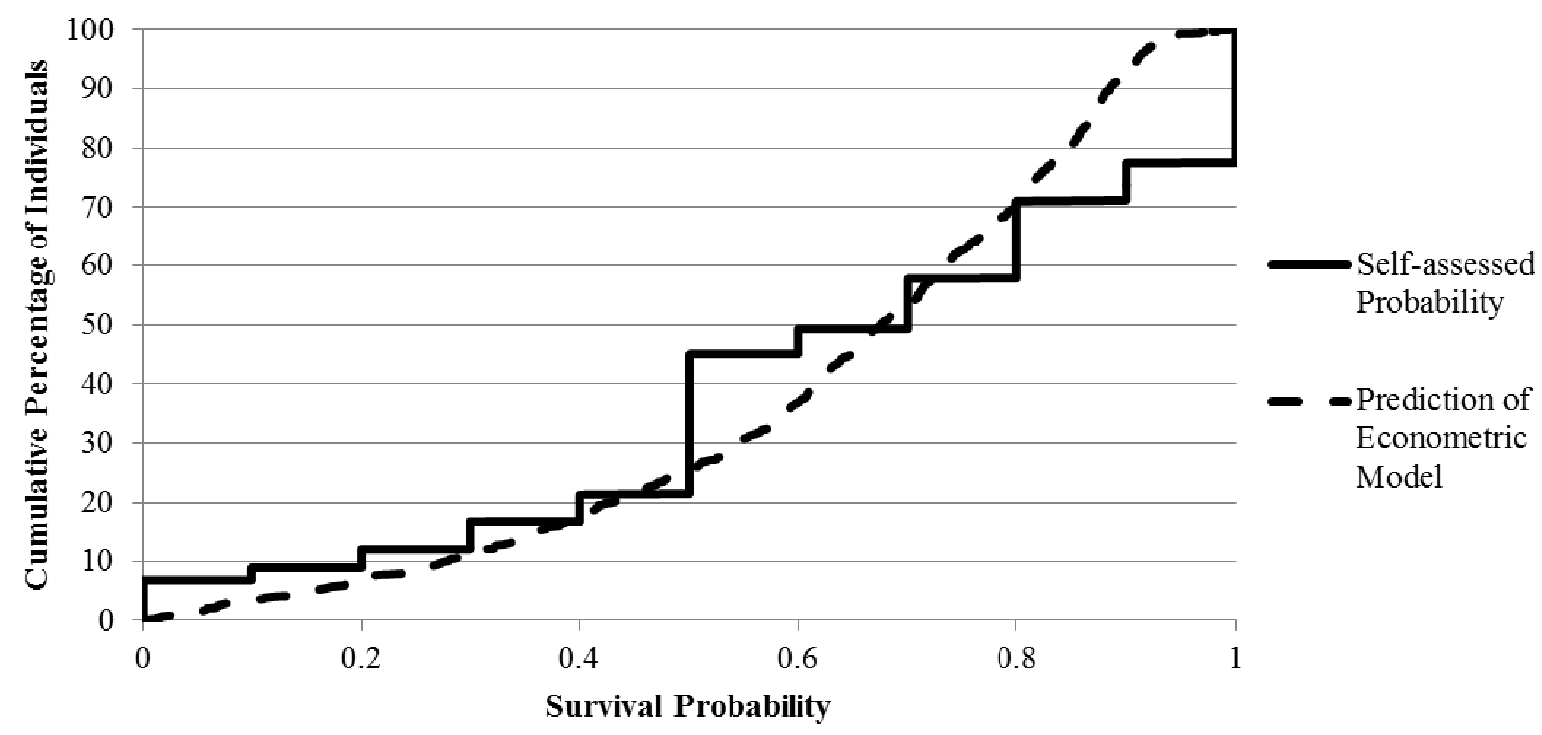


Figure 1A: Predicted and Self-Assessed Probability of Living to Age 75 -

\section{Females}

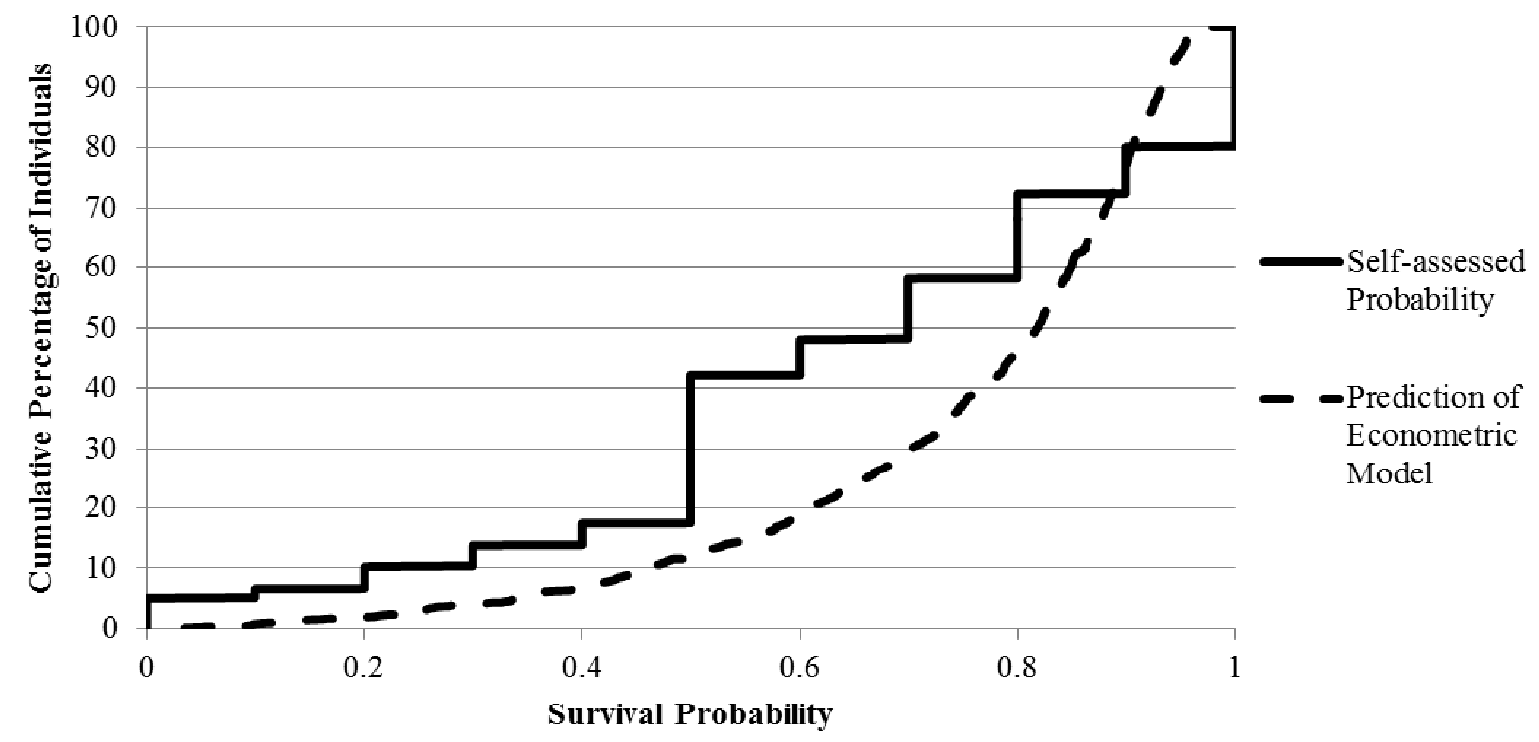


Figure 2: Pattern of Responses - Probability of Surviving to Age 75

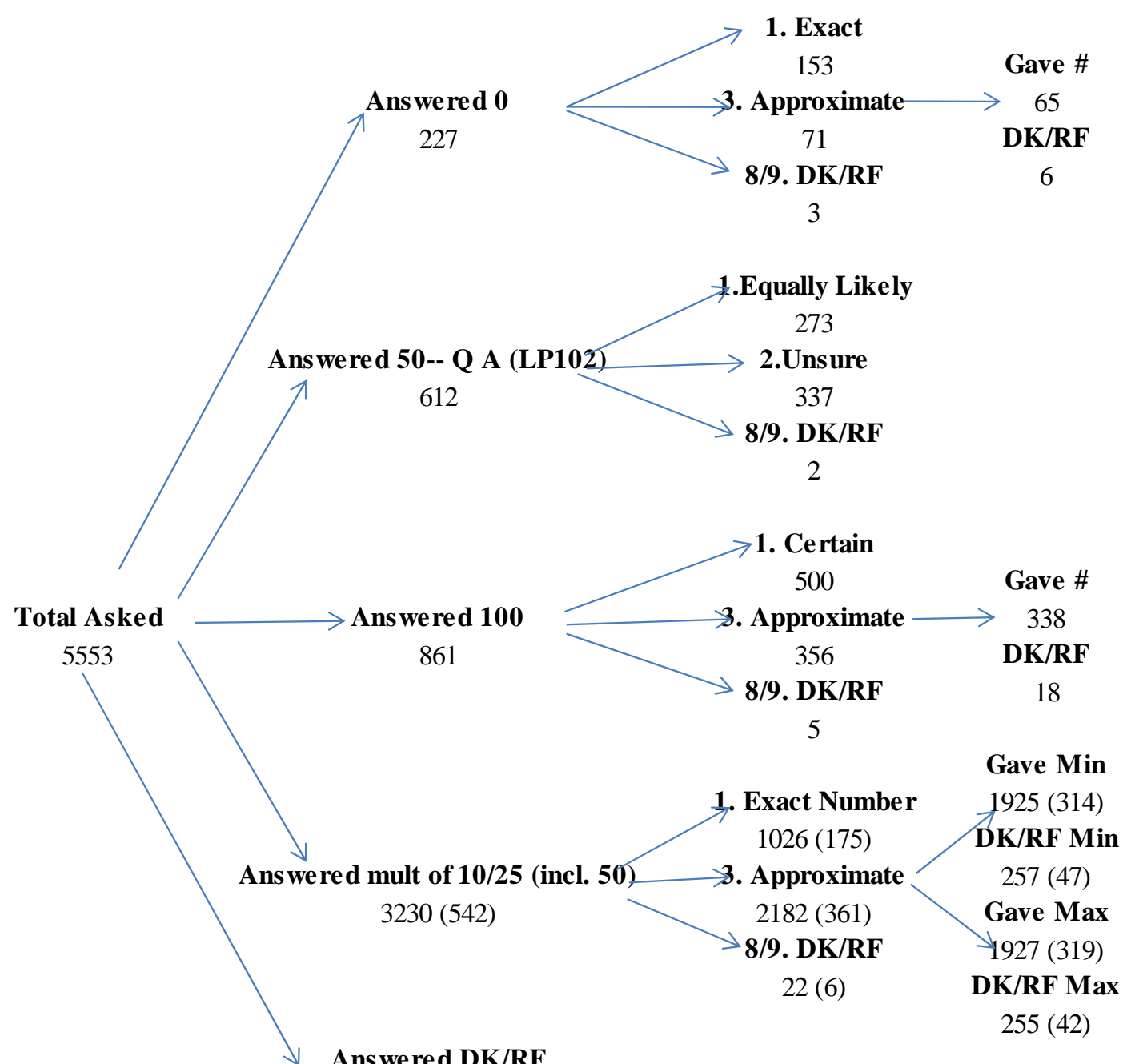

Answered DK/RF

213 
Figure 3A: Conditional Probability of Surviving to Age 85 - Males

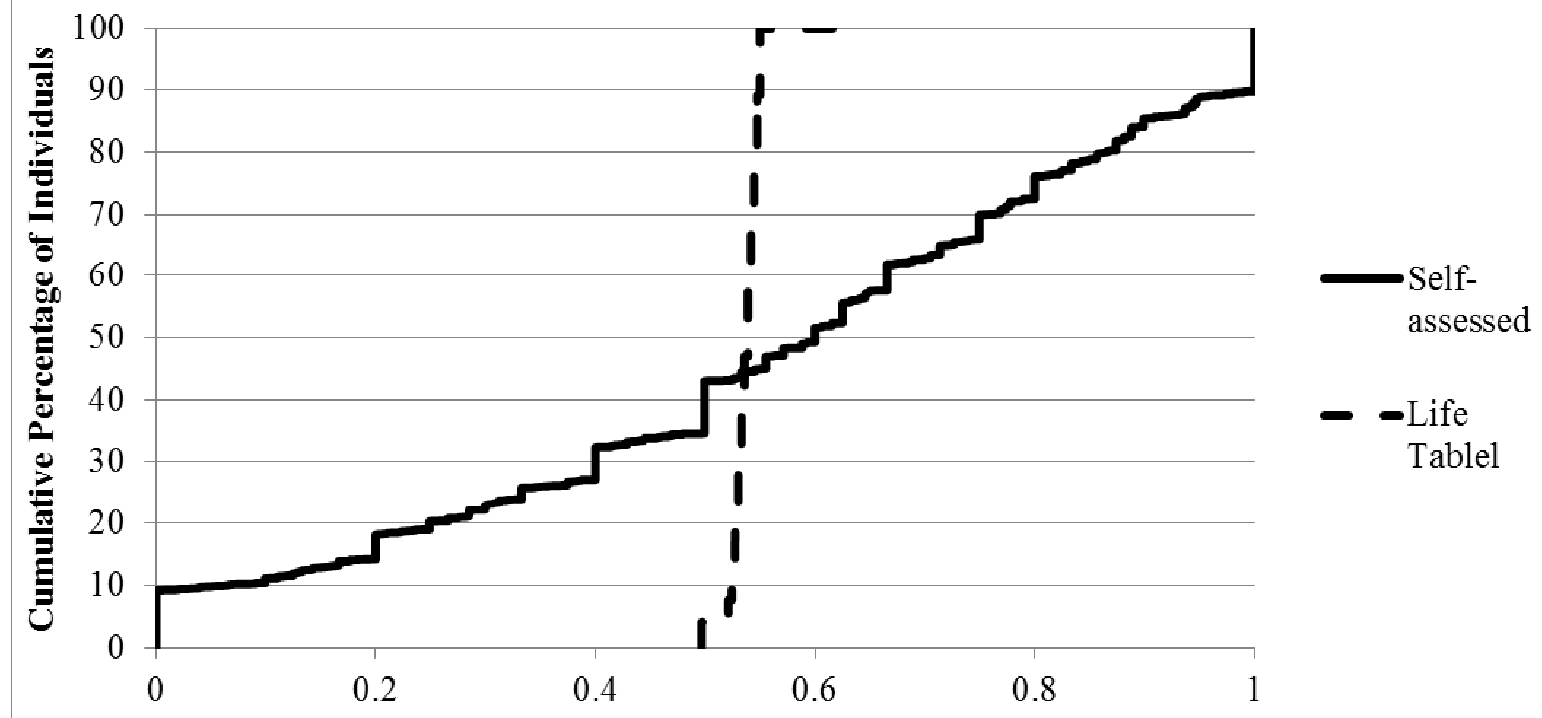

Probability of Surviving to Age 85, Conditional on Surviving to Age 75

Figure 3B: Conditional Probability of Surviving to Age 85 Females

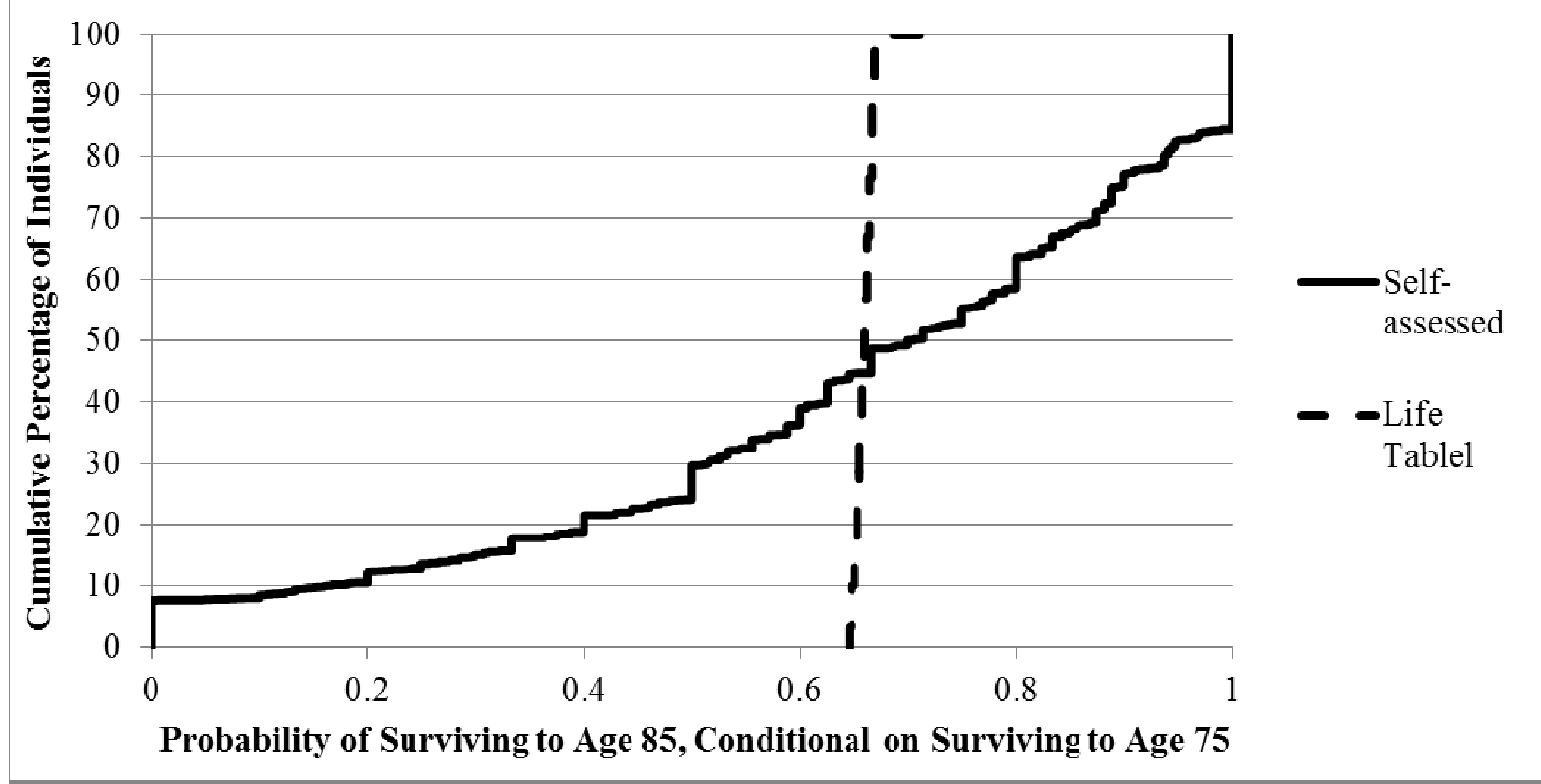



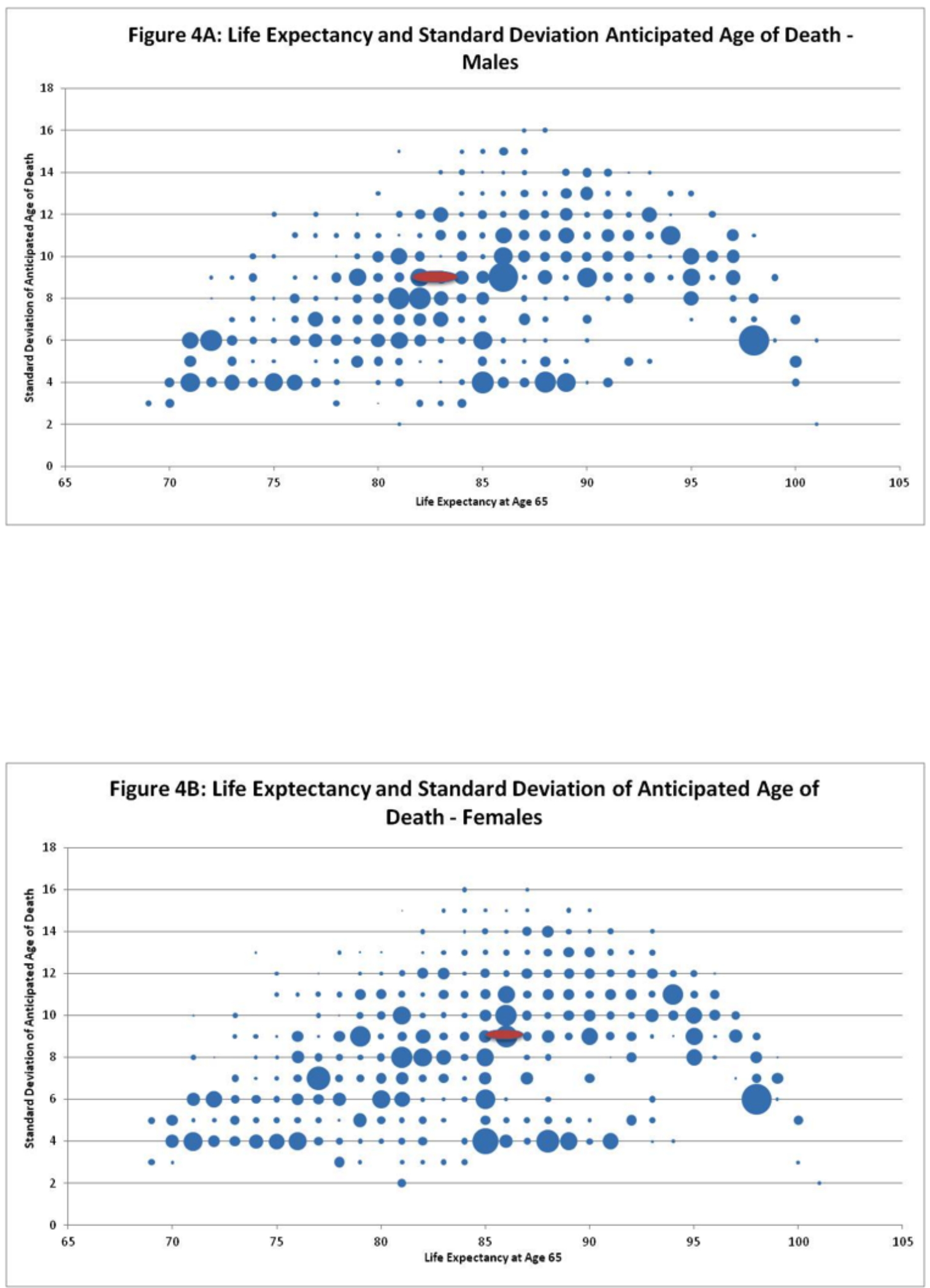


\section{RECENT WORKING PAPERS FROM THE CENTER FOR RETIREMENT RESEARCH AT BOSTON COLLEGE}

How Does the Personal Income Tax Affect the Progressivity of Oasi Benefits?

Norma B. Coe, Zhenya Karamcheva, Richard Kopcke, Alicia H. Munnell, November 2011

The Pension Protection Act of 2006 and Diversification of Employer Stock in Defined Contribution Plans

Gary V. Engelhardt, November 2011

Prescription Drug Insurance Coverage, Drug Utilization, and Cost-Related NonAdherence: Evidence from the Medicare Part D Expansion

Gary V. Engelhardt, November 2011

Social Security on Auto-Pilot: International Experience with Automatic Stabilizer Mechanisms

Barry Bosworth and R. Kent Weaver, November 2011

The Impact of Unemployment Insurance Extensions on Disability Insurance Application and Allowance Rates

Matthew S. Rutledge, October 2011

Do Couples Self-Insure? The Effect of Informal Care on a Couple's Labor Supply

Norma B. Coe, Meghan Skira, and Courtney Harold Van Houtven, October 2011

How Prepared are State and Local Workers for Retirement?

Alicia H. Munnell, Jean-Pierre Aubry, Josh Hurwitz, and Laura Quinby, October 2011

Social Security Reform and Male Labor Force Participation Around the World Jocelyn E. Finlay and Günther Fink, September 2011

Corporate Pension Plan Investments in Alternative Assets: Determinants and Consequences

Divya Anantharaman, August 2011

Social Security Reform and Male Labor Force Participation Around the World Jocelyn E. Finlay and Günther Fink, June 2011

An In-Depth Look into Intergenerational Flows

Oksana Leukhina and Marika Santoro, May 2011

Who Retires Early?

Henry J. Aaron and Jean Marie Callan, May 2011

All working papers are available on the Center for Retirement Research website (http://crr.bc.edu) and can be requested by e-mail (crr@bc.edu) or phone (617-552-1762). 